\title{
Management of Rupture of Membranes at Term in Low-Risk Obstetric Population
}

\author{
TARIK Y. YAMANI, CABOG,FICS, HASSAN'A. NASRAT, FRCS(ED), FRCOG, \\ and BaHAa A. ABALKHail, PhD* \\ Department of Obstetrics and Gynaecology, and Department of Community Medicine \& \\ Primary Health Care*, Faculty of Medicine \& Allied Sciences, \\ King Abdulazi: University, Jeddah, Saudi Arabia
}

\begin{abstract}
Objective: To compare the outcomes of expectant versus active management of patients presenting with premature rupture of membranes (PROM) at term.

Design: Observational case-controJ study over a period of 30 months.

Setting: King AbduJaziz University Hospital, Jeddah, Saudi Arabia.

Subjects: All obstetric patients with no obstetric risk factors other than PROM at term were included in the present study. Each patient was matched with a control case who had started labor with intact membranes.

Outcome Measures: Duration of Jabor, fetal distress, intrapartum pyrexia, rate of cesarean section delivery, and Apgar scores at birth.

Results: The duration of Jabor was shorter in patients with PROM compared to the control group, but the difference was not statistically significant. Furthermore, cesarean section rate was $4.5 \%$ in the PROM group versus $7.6 \%$ in the control group. Among patients with PROM who received active management, the rates of intrapartum pyrexia and cesarean sections were almost twice that in patients who were managedexpectantly.

Conclusion: In the absence of other maternal and/or obstetric risk factors, PROM does not seem to constitute additional obstetric risks. Furthermore, expectant management of PROM in anticipation of spontaneous uterine contractions increases the changes of normal delivery without an increase in fetal and/ or maternal morbidity.
\end{abstract}

Keywords: PROM, Fetal distress, Emergency cesarean section.

\section{Introduction}

Premature rupture of membranes (PROM) at term is defined as rupture of membranes before onset of uterine contraction!'! It occurs in about $7-15 \%$ of all pregnancies at term ${ }^{2.31}$ This variation in the reported incidence of PROM could be due to several factors related to the studied population and/or the criteria used for the diagnosis. The man-

Correspondence \& reprint requests to: Dr. Tarik Y. Yarnani, P.O. Box 6615, Jeddah 21452, Saudi Arabia Accepted for publication: 17June 1997. Received: 30 March J997. 
agement of PROM is still controversiall't-tl. An early induction of labor within 12 hours of PROM has been recommendedlvl. However, indiscriminate early induction is not without cornplicationf'J, Induced labor is more likely to be prolonged with increased risks of fetal and maternal complications and high rate of operative delivery!", More recently, an expectant approach for management of PROM has been suggested!"! The rationale behind such approach is to allow more time for cervical ripening to take place, thus enhancing the chance of vaginal delivery. Nevertheless, for many practicing obstetricians, the issue has not yet been resolved. Some studies have reported increased rate of maternal and/or fetal morbidity, mainly due to infection, in association with expectant management of PROMIIOJ. However, in many of such studies PROM was not the only complication, i.e., obstetric population with risk factors other than PROM were included. The objectives of the present study are: to examine whether PROM, per se, have an adverse effect on fetal and/or maternal outcome and to evaluate the outcome of expectant versus active management of PROM in the local population.

\section{Materials and Methods}

This was an observational case-control study conducted at King Abdulaziz University Hospital (KAUH) over a 3D-month period starting on I January 1993 till 30 August f995. During this period, all patients who presented to the labor room with PROM were- included, provided that they fulfilled the following criteria: (1) gestation age >37-41 weeks (based on reliable last menstrual period dating and/or second trimester ultrasound scan); (2) singleton pregnancy; and (3) cephalic presentation. Patients who had an indication for immediate delivery such as insulin-dependent diabetes mellitus, raised blood pressure, intrauterine growth retardation, previous cesarean sections (CS) or other risk factors, were excluded. The diagnosis of PROM was based on- the identification of "amniotic tluid pooling" in the vagina during an antiseptic vaginal speculum examination. In all patients with PROM, a high vaginal swab was taken for culture and sensitivity. Following speculum examination, digital vaginal examination was performed to assess cervical Bishop score!!!!", External cardiotocography (eTG) was then carried out for at least one hour to exclude uterine contractions or signs of fetal distress. If the CTG was reactive and no regular uterine contractions were recorded, the subsequent plan of management was made by the patient's own consultant. Cases where crossover in management occurred due to change in clinician's on-call duty rota were excluded from final analysis. Accordingly, patients received either an active or expectant management. In active management, labor was induced shortly after admission using oxytocin infusion according to standard labor ward protocol'!". Whereas in expectant management, patients following the diagnosis of PROM were transferred to the antenatal ward awaiting spontaneous onset of labor. During their stay in the hospital, observations were regularly made for signs and symptoms of chorioamnionitis (fever $>38^{\circ} \mathrm{C}$, tender uterus, offensive discharge, maternal and fetal tachycardia) and instructions were given for no vaginal examination'!".

Control cases were recruited from the patients who were admitted in active labor during the same study period, provided that they had intact membranes and fulfilled the same inclusion criteria as in the study group. 
In the study and control groups, several maternal and fetal variables were examined, namely: maternal age, gestational week, parity, and history of previous PROM. In patients with PROM, predicative variables (i.e., number of hours since rupture of membranes and cervical Bishop score) and the outcome variables (Le. fetal distress, intrapartum pyrexis, and mode of delivery) were also examined.

Statistical analysis was performed using SPSS statistical package for Windows (version 6.0) on an IBM compatible PC. Student $t$-test and $X^{2}$ test were used as appropriate. A P $<0.05$ was considered statistically significant.

\section{Results}

During the period of the study, 6,347 women were delivered at the KAUH obstetric unit. Two hundred women (3.2\%) presented with PROM, but only L32 women fulfilled the inclusion criteria. The rest $(n=68)$ were excluded due to the presence of obstetric risk factors other than PROM. A similar number of women $(n=132)$ who presented in labor with intact membranes were recruited as a control.

The mean age of women in the study and control groups were not significantly different. However, the means of gestational weeks at delivery and fetal birth weight were significantly greater in the control compared to the study group (see Table 1). In the study group 6 (4.5\%) -patients were delivered by CS because of failure to progress (3 cases) and fetal distress ( 3 cases). In the control group 10 (7.60/0) CS were performed for fetal distress ( 4 cases) and for failure to progress ( 6 cases). The difference was not statistically significant. Furthermore, the means of the Apgar scores (A-S) at one and five minutes were not significantly different between the two groups.

TABLE I. Maternal and obstetric variables in the study and control groups.

\begin{tabular}{|l|c|c|c|}
\hline \multicolumn{1}{|c|}{ Variable } & $\begin{array}{c}\text { Study Group } \\
(\mathrm{n}=132)\end{array}$ & $\begin{array}{c}\text { Control Group } \\
(\mathrm{n}=132)\end{array}$ & P Value \\
\hline Gestational age (weeks) & $38.6 \pm 3 . \mathrm{J}$ & $39.8 \pm 2.3$ & 0.001 \\
\hline Parity & $3.5 \pm 2.9$ & $3.2 \pm 2.4$ & $\mathrm{NS}$ \\
\hline Duration of labor (hours) & $6.5 \pm 3.9$ & $7.4 \pm 9.1$ & $\mathrm{NS}$ \\
\hline Intrapartum pyrexia & $3(2.3 \%)$ & ---- & ---- \\
\hline Vaginal delivery & $126(95.50 / 0)$ & $122(92.40 / 0)$ & NS \\
\hline Cesarean section & $6(4.50 / 0)$ & $10(7.60 / 0)$ & NS \\
\hline A-S at 1 min. & $8.2 \pm 1.4$ & $8.3 \pm 1.4$ & NS \\
\hline A-S at 5 min. & $9.0 \pm 1.0$ & $9.4 \pm 1.7$ & NS \\
\hline Birth weight $(\mathrm{g})$ & $3198 \pm 421$ & $3255 \pm 472$ & 0.003 \\
\hline
\end{tabular}

Data are given as mean $( \pm \mathrm{SD})$ and percentage as appropriate. A-S $=$ Apgarscore at 1 and 5 minutes; NS $=$ not significant; $\mathrm{n}=$ number.

The duration of labor in the "control group" (7.4 \pm 9.1 hours) was more prolonged as compared with the study group $(6.5 \pm 3.9$ hours $)$, but the difference was not statistically significant, respectively. Maternal pyrexia developed during labor in 3 cases in the study versus none in the control group. In the study group 88 women $(66.7 \%)$ were managed expectantly while 44 women (33.30/0) were actively managed. Table 2 shows the studied variables in the expectant and actively managed groups. There was no differ- 
ences between the two groups regarding the means of age, parity, gestational age at delivery, number of primigravidae patients, previous history of PROM, and cervical Bishop scores. As expected, the duration of PROM was greater in the expectantly compared to the actively managed group $(\mathrm{P}=0.001)$.

TAD!.!. 2. Maternal variables in the study groups, expectant and active patient s.

\begin{tabular}{|l|c|c|c|}
\hline \multicolumn{1}{|c|}{ Variable } & $\begin{array}{c}\text { Expectant } \\
(\mathrm{n}=88)\end{array}$ & $\begin{array}{c}\text { Active } \\
(\mathrm{n}=44)\end{array}$ & P Value \\
\hline Age (years) & $20.8 \pm 5.1$ & $26.8 \pm 4.6$ & NS \\
\hline Parity & $3.3 \pm 2.5$ & $3.3 \pm 2.0$ & NS \\
\hline Gestationa l age (weeks) & $39.0 \pm 2.2$ & $39.0 \pm 1.0$ & NS \\
\hline Nulliparas & $34(38.6 \%)$ & $16(36.4 \%)$ & NS \\
\hline Multiparas & $54(61.4 \%)$ & $28(63.6 \%)$ & NS \\
\hline Previous PROM & $1(1.1 \%)$ & $1(2.2 \%)$ & NS \\
\hline Duration of PROM (hours) & $9.8 \pm 7.9$ & $6.2 \pm 5.7$ & 0.001 \\
\hline Bishop sco re & $4.5 . \pm 1.9$ & $4.7 \pm 2.2$ & NS \\
\hline
\end{tabular}

Data are given as means $( \pm \mathrm{SO})$ and percentage as appropriate. NS $=$ not Sg nificant. $\mathrm{n}=$ number.

In patients with PROM who were managed expectantly, 75 women $(85.2 \%)$ went into spontaneous labor within 24 hours. Thirteen women (14.8\%) did not enter labor until 24 hours later from the time of rupture of membranes. Table 3 shows the outcome variables in the expectant and actively managed groups. There was no significant difference in duration of labor, fetal distress, intrapartum pyrexia, Apgar score, and fetal birth weight between the two groups. The incidence of CS (all due to failure to progress) in the actively managed group was almost twice that in the expectantly managed one. However, the difference was not statistieally significant, which could be due to the small number of patients included in the active group. There were 14 women $(15.9 \%)$ in the expectant versus 2 women $(4.5 \%)$ in the active group who had positive high vaginal swab culture for candidiasis $(\mathrm{P}=0.04)$. No other pathogens were isolated.

T AD!.!. 3. Delivery variab le of the study gro ups. expectant and active patient s.

\begin{tabular}{|l|c|c|c|}
\hline Variable & $\begin{array}{c}\text { Expectant } \\
(\mathrm{n}=88)\end{array}$ & $\begin{array}{c}\text { Active } \\
(\mathrm{n}=44)\end{array}$ & P value \\
\hline Duration of labor (hours) & $6.3 \pm 3.6$ & $7.0 \pm 4.4$ & NS \\
\hline Intrapartum pyrexia & $1(1.1 \%)$ & $2(4.5 \%)$ & NS \\
\hline Intrapartum fetal distre ss & $13(14.8 \%)$ & $6(13.6 \%)$ & NS \\
\hline Vaginal deli very & $85(96.6 \%)$ & $41(93.2 \%)$ & NS \\
\hline Cesarean section & $3(3.4 \%)$ & $3(6.8 \%)$ & NS \\
\hline ASI $<7$ & $(6.7 \%)$ & $(6.7 \%)$ & $-\cdots$ \\
\hline AS 5<7 & $(1.1 \%)$ & ---- & 0.04 \\
\hline Positi ve candidiasis & $14(15.9 \%)$ & $2(4.5 \%)$ & NS \\
\hline Sin h weig ht $(g)$ & $3241 \pm 434.4$ & $3156.76 \pm 408.8$ & \\
\hline
\end{tabular}

Data are given as mean $\mathrm{I} \pm \mathrm{SO}$ ) and percentage as appropriate. A-S $=$ Apgar score at $\mathrm{I}$ and $\mathbf{5}$ minutes; NS $=$ not significant; $\mathrm{n}=$ number. 


\section{Discussion}

PROM before onset of uterine contracts is not uncommonly associated with obstetric risk factors such as unstable lie, multiple pregnancy, and polyhydramnios. However, in the majority of cases of PROM there is no obvious cause(s). Subclinical intrauterine infections have been proposed as a predisposing factor for PROM[15,16]. In the presence of strong evidence of intra-amniotic infection, prompt delivery is advocated. However, in the absence of such evidence or other obstetric indications for immediate delivery, the most appropriate choice of management of PROM is still controversial. Immediate induction of labor in case of PROM used to be a strongly advocated standard practice to avoid potential complications of intrauterine infection and oligohydramnios. However, the results from earlier studies that lend to support to such approach were not uncommonly driven from mixed obstetric populations who might had risk factors other than PROM which, in itself, demand immediate delivery. Therefore, the objectives. of the present study were to examine pregnancy outcomes when PROM is the only risk factor in an otherwise normal obstetric population. The results were generally in agreement with those from other studies that showed no increase in maternal and/or fetal morbidity in association with expectant management of PROM(17,18J. Furthermore, as the results of the present study show, most patients (85.20/0) who were offered expectant management went into spontaneous labor within 24 hours. Even in those women $(n=13)$ who continued beyond this period, they all delivered spontaneously with no significant fetal and/or maternaJ morbidity. Similar findings have been obtained in a recent report that have examined the outcome following a prolonged period of PROM in a larger studied popularionlt"",

In the present study, the duration of labor was shorter with higher percentage of patients with PROM having a vaginal delivery compared with the control group. This could be explained by the fact that patients with PROM have had more time to go through the early "latent phase" of labor before they were physically transferred to the delivery suite. However, this by itself may be advantageous to patients since the time a patient spends in the labor room being subjected to all necessary interventions is probably the most distressing period in the process of delivery.

Traditionally, the risk of intrapartum pyrexia and chorioamnionitis has been related to the duration of PROM. However, recent studies have shown that a vaginal examination has a strong association with chorioamnionitislv". Our approach in KAUH is to avoid a digital vaginal examination and to only perform it if it is necessary and under antiseptic precautions. This could explain the rather lower incidence of pyrexia observed in the expectantly compared to that in the actively managed group. Indeed, induced patients had a higher chance of developing pyrexia; this may be due to longer hours in labor with more frequent vaginal examinations and increased duration of internal fetal monitoring.

The emergency CS rate due to failure to progress in the actively managed group was almost twice that in the conservati vely managed one. The lack of statistical significance, which may be due to the small number of patients, should not undermine the clinical significance of such finding. It highlights the risk of failure of vaginal delivery associated with induction of labor in such cases. 
In conclusion, the results of the present study suggest that in the absence of other maternal and/or fetal risk factors, PROM per se does not constitute an additional obstetric risk. Furthermore, expectant management of PROM at term enhances the patient's chance of having a vaginal delivery with no increase in maternal and/or fetal morbidity, provided that a vaginal examination is withheld and only restricted to a minimum requirement.

\section{References}

[I] Grant JM, Serle E, Mahmood T, Sarmandal P, Conway DI. Management of prelabour rupture of the membranes in term primigravidae: a report of a randomized prospective trial. $\mathrm{Br} \mathrm{J}$ Obstet Gynaecol 1992: 99(7): 557-562.

[2] Premature rupture of the membranes [editorial]. Br Med J 1979; 1(6172): 1165-1166.

[3] Lanier LR, Scarbrough RW, Fillingim DW, et al. Incidence of maternal and fetal complications associated with rupture of the membranes before onset of labour.J Obstet Gynecol 1965; 93: 398.

[4] Marshall VA. Management of premature rupture of membranes at or near term. J Nurse Midwifery 1993; 3: 140-145.

[5] Tamsen L, Lyrenas S, Cnattingius S. Premature rupture of the membranes--intervention or not. Gynecol Obstet Invest 1990: 29(2): 128-131.

[6] Wagner MV, Chin VP, Peters CJ, Drexler B, Newman LA. A comparison of early and delay induction of labor with spontaneous rupture of membranesat term. Obstet Gynecol 1989; 74(1): 93-97.

[7] Kappy KA, Cetrulo CL, Knuppel RA, Ingardia CJ, Sbarra AJ, Scerbo JC, Mitchell GW. Premature rupture of membranes at term. A comparison of induced and spontaneous labors. J Reprod Med 1982; 27(1): 29-33.

[8] Evaldson G, Lagrelius A, Winiarski J. Premature rupture of the membranes. Acta Obstet Gynecol Scand 1980; 59(5): 385-393.

[9] Egan D, Oherlihy C. Expectant management of spontaneous rupture of membranes at term. J Obstet Gynecol 1988; 8: 243-247

[10] Russel KP, Anderson GW. The aggressive management of ruptured membranes. Am J Obstet Gynecol $1962 ; 83: 930-934$.

[II] Duff P, Huff RW, Gibbs RS. Management of premature rupture of membranes and unfavorable cervix in term pregnancy. Obstet Gynecol $1984 ; \mathbf{6 3}(\mathbf{5})$ : $697-702$.

[12] Bishop ED. Pelvic scoring for elective induction. Obstet Gynecol 164; 24: 266-268.

[13] Seitchik J, Castillo M. Oxytocin augmentation of dysfunctional labor. I. Clinical data. Am J Obstet Gynecol 1982; 144(8): 899-905.

[14] Grant J, Keirse MJ. Prelabor rupture of membranes at term. In Chalmers I, Enkin M, eds. Effective care in pregnancy and childbirth. Oxford University Press, 1989: 1112

[15] Minkoff H, Grunebaum AN, Schawrz RH, Feldman J, Cummings M, Crombleholme W, Clark L, Pringle G, McCormack WM. Risk factors for prematurity and premature rupture of membranes: a prospective study of the vaginal flora in pregnancy. Am J Obstet Gynecol 1984; 150(8): 965-972.

[16] Naeye RL. Factors that predispose to premature rupture of the fetal membranes. Obstet Gynecol 1982; 60(1): 93-98.

[17] Cammu H, Verlaenen H, Perde MP. Premature rupture of membranesat term in nulliparous women: a hazard? Obstet Gynecol 1990; 76(4): 671-674.

[18] Daikoku NH, Kaltreider DF, Johnson TR Jr, Johnson JW, Simmons MA. Premature rupture of membranes and preterm labor: neonatal infection and perinatal mortality risks. Obstet Gynecol 1981; 58 (4): 417-425.

[19] Ladfors L, Mattsson LA, Eriksson M, Fall O. A randomised trial of two expectant managements of prelabor rupture of membranes at 34 to 42 weeks. Br J Obstet Gynaecol 1996: 103(8): 755-762.

[20] Shutte MF, Treffers PE, Kloosterman GJ, Soepatmi S. Management of premature rupture of membranes: the risk of vaginal examination to the infant. Am J Obstet Gynecol 1983; 146(4): 395-400. 


\section{تدبيـر نـزول السائل الأ منيـوسي في مرضهى حــوامل قليلي الخطوره

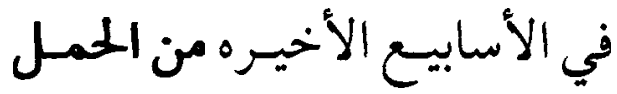

\section{ثلارق ياني ، حسن نصرت - ل بهاء أبا الحيليل}

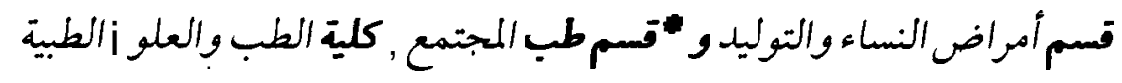

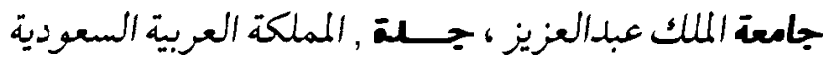

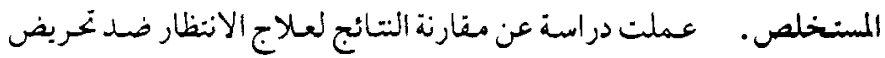

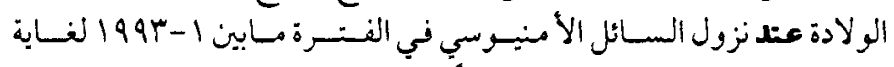

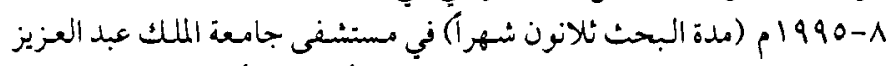

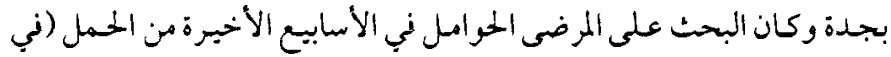

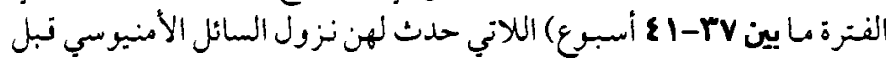

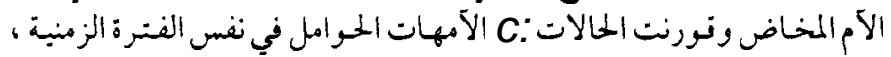

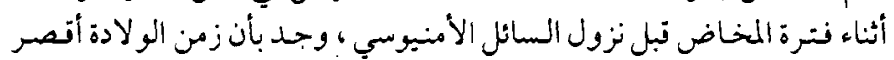

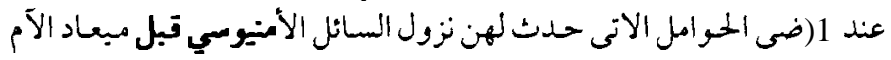

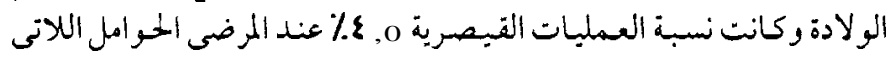

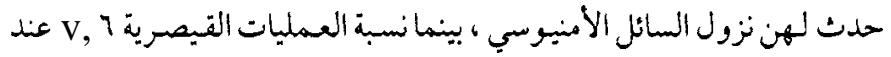

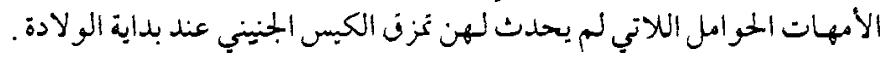

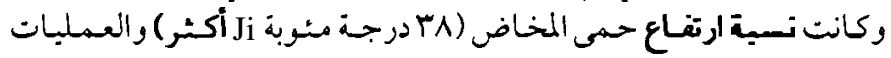

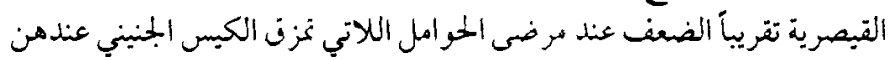

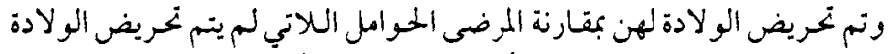

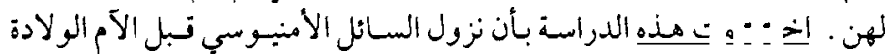

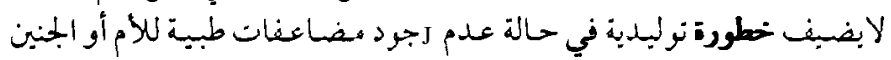

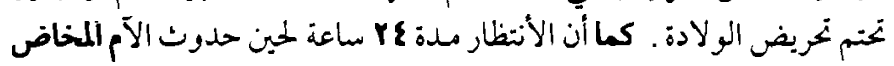

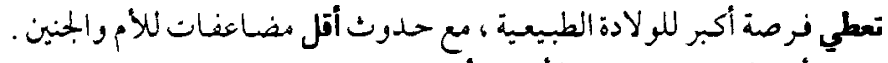

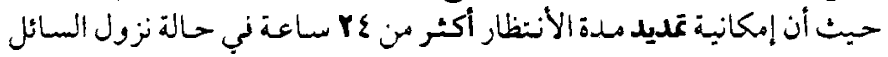

$$
\begin{aligned}
& \text { الأمنيوسى تحتاج لدراسة أخرى مستفيضة . }
\end{aligned}
$$

